\title{
Imágenes de desigualdad en Chile: El impacto de factores económicos y políticos*
}

\author{
Images of Inequality in Chile: The Impact of \\ Economic and Political Factors
}

\author{
Carolina Segovia** \\ Ricardo Gamboa ${ }^{* * *}$
}

Recibido: 23/01/2015

Aprobado: 14/07/2015

Disponible en línea: 30/11/2015

\begin{abstract}
Resumen
¿Cuán desigual perciben los ciudadanos que es la sociedad chilena? ¿Ha cambiado la imagen que los chilenos tienen de esa desigualdad en los últimos años? ¿Qué factores determinan los niveles de desigualdad percibidos? El presente trabajo aborda estas preguntas utilizando datos provenientes de las encuestas del Centro de Estudios Públicos (CEP). Los resultados muestran que los chilenos perciben mayoritariamente que viven en una sociedad desigual, que esas percepciones han variado poco entre 2000 y 2013, aunque muestran una tendencia levemente más positiva para 2013 y que los principales determinantes de esas percepciones son económicos y no políticos.
\end{abstract}

\begin{abstract}
How unequal is Chilean society perceived to be by its citizens? Has this image changed over the last few years? What explains the levels of inequality perceived? Using data from public opinion surveys we consider these questions. Results show that Chileans believe they live in an unequal society, that those perceptions have remained stable between 2000 and 2013, with a small improvement by 2013 , and that those perceptions can be explained by economic -and not political-factors.
\end{abstract}

doi:10.11144/Javeriana.papo20-2.idci

* Artículo de investigación. La realización de este trabajo ha sido posible gracias al financiamiento otorgado al Proyecto FONDECYT No 1120733.

** Socióloga y MA en Ciencia Política de la Pontificia Universidad Católica de Chile y Ph.D. en Ciencia Política de la Universidad de Michigan. Profesora Asociada de la Escuela de Ciencia Política de la Universidad Diego Portales y Directora del Instituto de Investigación en Ciencias Sociales (ICSO) de la misma universidad. Correo electrónico: carolina.segovia@udp.cl

*** Abogado y MA en Ciencia Política de la Pontificia Universidad Católica de Chile y Doctor en Ciencia Política de la Universidad de Tübingen, Alemania. Profesor Asociado del Instituto de Estudios Internacionales de la Universidad de Chile. Correo electrónico: rgamboa@uchile.cl 


\section{Palabras clave}

imágenes de desigualdad; cambios en percepciones; determinantes de percepciones de desigualdad; Chile

\section{Cómo citar este artículo:}

Segovia, C., \& Gamboa, R. (2015). Imágenes de desigualdad en Chile: El impacto de factores económicos y políticos. Papel Político, 2O(2), 481-50o. http://dx.doi.org/10.11144/ Javeriana.papo20-2.idci

\section{Keywords}

images of inequality; trends in perceptions of inequality; correlates of perceptions of inequality; Chile 


\section{Introducción}

La desigualdad de ingresos en Chile se ha mantenido relativamente estable los últimos 25 años. En efecto, hacia 1990 el índice de GINI para el conjunto del país se estimaba en 0,57, mientras que en 2011 alcanzaba un valor de 0.54 (CASEN, 2011). Estos indicadores ubican a Chile como uno de los países con mayor nivel de desigualdad económica en la región y del grupo de países pertenecientes a la OCDE (OCDE, 2011). La evolución de este indicador contrasta fuertemente con el sostenido e importante descenso de las cifras de pobreza, que pasaron de casi $40 \%$ a 14\% en el mismo período (CASEN, 2011).

Por otra parte, pese a este alto y constante nivel de desigualdad, no fue sino hasta la pasada elección presidencial de 2013 que este se transformó en un tema central del debate político. Sin duda habían algunas indicaciones de que el tema adquiriría centralidad, por ejemplo, en la propuesta de un salario ético que formuló Monseñor Goic en 2007 (ORBE, 2007) y en los discursos del movimiento estudiantil que desde 2011 demandó una restructuración del sistema educativo chileno (Segovia \& Gamboa, 2012). Sin embargo, a nivel de programas políticos, el tema emergió con fuerza solo en la campaña de 2013 y se ha mantenido como un eje central del discurso en la agenda programática del actual gobierno de Bachelet.

En este contexto en el cual el tema de la desigualdad económica ha adquirido un lugar central en la discusión política, este trabajo busca ampliar el entendimiento de la materia y estudiar dos cuestiones conexas y centrales al respecto: a) cंcuánta desigualdad económica perciben los chilenos?, y b) ¿qué factores determinan esa percepción de desigualdad? Nos concentramos en estas preguntas porque pese a la relevancia que el tema ha adquirido en la agenda política del país en los últimos años y lo central de las preguntas que guían el trabajo, a la fecha existen pocos estudios que hayan avanzado en el tema para el caso chileno (Blofield \& Luna, 2011; Castillo, Miranda, \& Carrasco, 2012). Asimismo porque al preguntar cuánta desigualdad perciben los ciudadanos en la sociedad chilena y si esa percepción ha variado en el tiempo, avanzamos en determinar la magnitud de la desigualdad percibida por las personas, qué tan cercanas son esas imágenes respecto a las cifras económicas mencionadas y cómo esas percepciones varían en el tiempo. Al analizar los factores que determinan los niveles de desigualdad percibidos por los chilenos, abordamos no solo una pregunta central de la investigación comparada, sino que también ampliamos la literatura existente para el caso de Chile, que a la fecha ha estudiado principalmente la relevancia de la posición económica y social de los individuos y sus preferencias políticas como factores explicativos de la percepción de desigualdad (Blofield \& Luna, 2011; Castillo et al., 2012). En este trabajo y buscando profundizar en el tema, incluimos otros factores económicos y políticos en el análisis que, según la investigación comparada, son relevantes para explicar la percepción de desigualdad, pero que hasta la fecha no han sido analizados para el caso chileno. 
Consideramos los resultados obtenidos por encuestas realizadas por el Centro de Estudios Públicos (CEP) en los años 2000, 2009, 2012 y 2013, que incluyen preguntas asociadas a la desigualdad económica. En particular, utilizaremos una pregunta que permite a los entrevistados una evaluación visual de la desigualdad en el país y que no requiere -como en otras medidas-un nivel de conocimiento amplio sobre la materia. A partir de estos resultados analizaremos el impacto que tienen factores económicos y políticos -que en la investigación comparada aparecen como los más relevantespara el caso de Chile.

En el artículo exponemos la discusión teórica principal de la literatura comparada sobre medición de percepciones de desigualdad. Luego presentamos los argumentos relacionados con el impacto que tienen factores económicos y políticos sobre las percepciones de desigualdad, de lo cual derivamos las principales hipótesis del estudio. Después describimos la metodología de análisis y los datos utilizados, presentamos y discutimos los resultados obtenidos y finalmente exponemos nuestras conclusiones.

\section{Medición de las percepciones de desigualdad}

¿Cuánta desigualdad perciben los ciudadanos? Existe en general, la presunción de que las personas no saben o no conocen cuáles son las diferencias de ingresos entre distintos grupos de la sociedad y por tanto, que tienen una estimación equivocada, habitualmente menor, de los niveles de desigualdad económica (Bartels, 2008; Page \& Jacobs, 2009). Esta presunción se basa habitualmente en argumentos y evidencia empírica asociados a los bajos niveles de conocimiento que en general, caracterizarían a la opinión pública (Converse, 2000; Zaller, 1992).

La investigación comparada sobre percepciones de desigualdad de los ciudadanos ha utilizado tres instrumentos principales. El primero y más usado se basa en la pregunta (que se ha hecho en múltiples estudios de opinión) sobre el grado de acuerdo o desacuerdo que tienen las personas (utilizando una escala Lickert) con la afirmación de si 'las diferencias de ingresos en [Chile] son demasiado grandes'. La investigación basada en este tipo de pregunta muestra que los niveles de conocimiento sobre la desigualdad son bajos y poco precisos (Bartels, 2008; McCall, 2005; 2009; 2013). Esto puede estar asociado, sin embargo, más que a falta de conocimiento, a la utilización de medidas poco discriminantes. Un primer problema de esta pregunta es que mayorías significativas de entrevistados en distintos países, tienden a estar de acuerdo con la afirmación, generando resultados que discriminan poco y que no permiten distinguir claramente las percepciones de los ciudadanos. El segundo, es que combina en un solo ítem la percepción sobre cantidad de desigualdad con una actitud evaluativa hacia ella. Al señalar que la desigualdad es 'demasiado' grande, el entrevistado puede estar haciendo un juicio de cantidad, pero también una evaluación 
negativa de esos niveles de desigualdad (McCall, 2005). En síntesis, este instrumento ha sido objeto de fuertes críticas respecto a su confiabilidad y validez, por tanto, no lo consideramos útil para este trabajo

El segundo instrumento se basa en las preguntas sobre cuánto se estima que ganan las personas que trabajan en algunas ocupaciones. Con estos datos es posible estimar una brecha de ingresos entre ocupaciones de más alto y más bajo prestigio social. En una investigación realizada en Estados Unidos utilizando este tipo de preguntas, Page y Jacobs (2009) muestran que las personas perciben grandes diferencias en los ingresos recibidos por diferentes ocupaciones y que estas estimaciones son bastante acertadas cuando se las compara con datos oficiales para esos mismos grupos. Page y Jacobs muestran además, que las brechas percibidas entre aquellos grupos que ganan más y aquellos que ganan menos han aumentado y que esta tendencia, aunque levemente desfasada en el tiempo, se relaciona con la trayectoria de los niveles de inequidad observados en Estados Unidos (Page \& Jacobs, 2009). Este parece ser entonces, un mejor instrumento para medir las percepciones de desigualdad (Kelley \& Evans, 1993; Kelley \& Zagorski, 2004; Page \& Jacobs, 2009). Estas preguntas, sin embargo, han sido implementadas solo en dos oportunidades en las encuestas del CEP, por lo que no son tan apropiadas para evaluar el cambio en las percepciones de desigualdad.

La tercera forma de medir las percepciones de desigualdad -y que utilizaremos en este trabajo- se basa en un tipo de pregunta incluido en las encuestas que le pide a los entrevistados observar unas imágenes, leer sus descripciones y señalar qué tipo de sociedad es el país (Chile) hoy. Esta medición permite evaluar las imágenes de desigualdad de los ciudadanos con respecto al país en el que viven. La Figura $\mathrm{N}^{\circ} 1$ muestra la forma en que se realiza esta pregunta.

Este instrumento de medición de percepciones fue desarrollado por Evans, Kelley y Kolosi (1992) y se ha incluido en los estudios sobre desigualdad económica del International Social Survey Programme (ISSP) desde 1992, y del CEP en Chile desde el año 2000. Aunque ha sido poco utilizada en la investigación comparada, esta pregunta tiene una serie de ventajas. Primero, no requiere de conocimiento directo por parte de los entrevistados para contestar cómo perciben los ciudadanos la sociedad en que viven. La respuesta puede ser construida utilizando distintas fuentes de información y buscan evaluar cuán igual o desigual se percibe que es la sociedad en su conjunto. De acuerdo a Evans, Kelley y Kolosi, la investigación muestra que las personas desarrollan imágenes de las sociedades en las que viven y que esas imágenes son medibles (1992). 
Figura $N^{\circ}$ 1: Imágenes de desigualdad

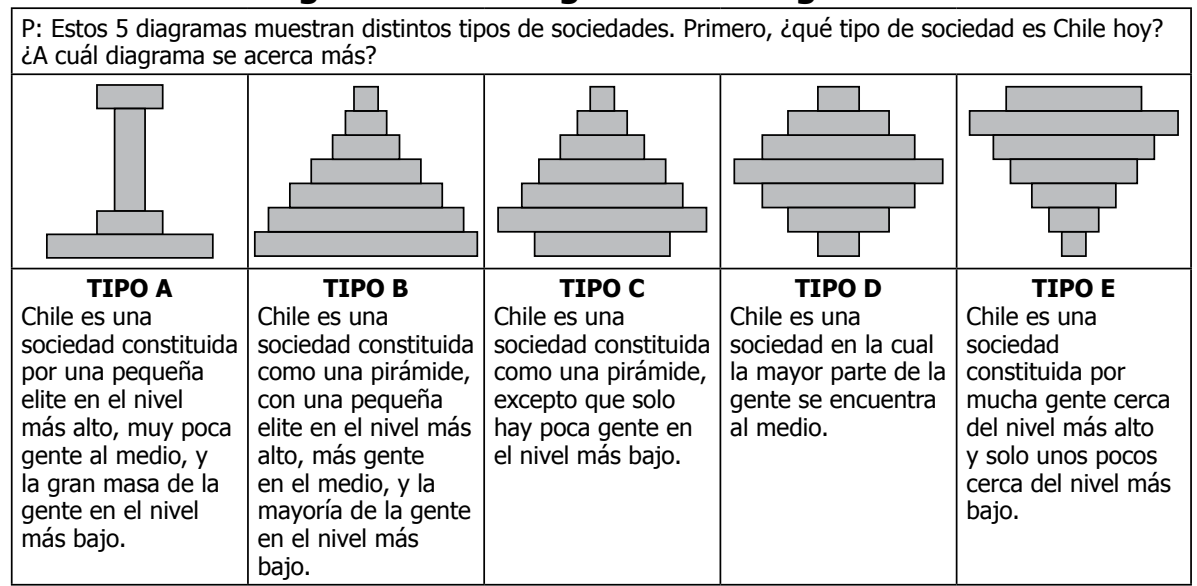

Fuente: Centro de Estudios Públicos (2000; 2009; 2012; 2013)

Esta pregunta mide percepciones sin confundirlas con la evaluación que los individuos pueden tener de esa desigualdad, uno de los problemas de las preguntas que utilizan escalas de acuerdo, como se explicó anteriormente. En efecto, esta pregunta solo busca conocer cómo las personas perciben la sociedad en la que viven. Si se quisiera evaluar la valoración de los niveles de desigualdad (p.e., preguntar qué tan legítimos son), entonces se podrían incluir otras preguntas sobre por ejemplo, cómo debería ser Chile. De esta manera no se confunden distintos tipos de evaluaciones en un solo ítem (Evans et al., 1992). Finalmente, esta pregunta es relativamente sencilla, ya que al presentar imágenes ayuda al entrevistado con respecto al texto que describe cada tipo de sociedad (Evans et al., 1992).

La poca evidencia de la que se dispone sobre esta forma de medir percepciones de desigualdad indica que las personas son capaces de distinguir el tipo de sociedad en la que viven y que esas percepciones corresponden con el nivel de desigualdad económica medido a través de indicadores como el GINI (Evans et al.,1992). Adicionalmente, esta pregunta ha demostrado su utilidad al evaluar percepciones de desigualdad en contextos políticos y sociales diversos, constituyendo así un instrumento válido y confiable (Cuneo, 1996; Castillo et al., 2012; Evans et al., 1992).

\section{Determinantes individuales de las percepciones de desigualdad}

En general, la investigación asociada a los determinantes de las percepciones de desigualdad económica puede ser dividida en dos grupos. Una primera línea de investigación se concentra en el estudio de los determinantes de la legitimidad de la desigualdad económica, esto es, explica que las personas asignen a una situación de desigualdad mayor o menor legitimidad (Austen, 1999; Blofield \& Luna, 2011; Cramer \& Kaufman, 2011; Kelley \& Evans, 1993). La segunda línea de investigación se concentra en el estudio de 
los determinantes de cuánta desigualdad perciben las personas (Bartels, 2008; Castillo et al., 2012; McCall, 2013; Page \& Jacobs, 2009).

Este trabajo se inscribe en la segunda línea mencionada y propone un modelo de análisis de las determinantes de las percepciones de desigualdad en Chile. Este es un tópico de primera importancia ya que, como lo ha demostrado la investigación comparada, las percepciones sobre desigualdad son determinantes de cuestiones políticamente relevantes, como los niveles de participación política y electoral (Schattschneider, 1960; Solt, 2008; 2010), el nivel de demanda de políticas redistributivas (Meltzer \& Richard, 1981) o las preferencias de las personas entre partidos de distinta tendencia ideológica (Anderson \& Singer, 2008; Anderson \& Beramendi, 2012)

Ahora bien, ¿qué determina las percepciones sobre los niveles de desigualdad? ¿Qué factores nos permiten explicar que algunos individuos perciban mayor desigualad que otros en sus sociedades? La investigación se ha centrado en dos conjuntos de variables a nivel individual que explicarían el nivel de desigualdad percibido por las personas: aquellos asociados a factores económicos y otros relacionados con actitudes políticas.

\section{El impacto de factores económicos en las percepciones de desigualdad}

La investigación ha mostrado que distintos tipos de factores económicos pueden estar asociados a las percepciones de desigualdad que reportan los ciudadanos. En primer lugar, se ha indagado en torno al impacto que el estatus socioeconómico de las personas (medido habitualmente por el nivel de ingreso y el nivel educacional) pueda tener en las percepciones de desigualdad. Existen aquí dos hipótesis que van en direcciones opuestas. Por una parte, para algunos autores se debe esperar una percepción de mayor desigualdad entre quienes poseen menores niveles de ingreso. Al ser los más afectados por la desigualdad, estos grupos percibirían una mayor desigualdad económica en la sociedad, exhibirían una mayor preocupación por esos niveles de desigualdad y tendrían una evaluación más negativa de ella que grupos con mayores niveles de ingresos (Evans et al., 1992; Schattschneider, 1960).

Por otra parte, se observa que la estimación de ingresos es más exacta entre los grupos de profesiones más cercanas en la vida cotidiana a los entrevistados (Page \& Jacobs, 2009) y que las percepciones de desigualdad se asocian positivamente a mayor ingreso y mayor nivel educacional (Castillo et al., 2012; Bartels, 2008; McCall, 2005; 2013; Page \& Jacobs, 2009). Esto estaría asociado a que las personas de ingresos y niveles educacionales altos tendrían un mayor conocimiento de los niveles y evolución de la desigualdad y podrían por lo tanto, generar estimaciones más precisas (Bartels, 2008; McCall, 2005). Como respuesta a estas expectativas dispares planteadas por la literatura, en este trabajo esperamos encontrar evidencia de una relación -que puede ser positiva o negativa- entre el estatus socioeconómico y las percepciones de desigualdad de los entrevistados. 
Cramer y Kaufman (2011) muestran que la percepción de los niveles de desigualdad en América Latina está influida de manera significativa por las percepciones económicas de los individuos. Es así como ellos encuentran que mientras más negativa sea la percepción de la situación económica actual y las expectativas a futuro, mayor será la evaluación negativa de la desigualdad (Cramer \&y Kaufman, 2011). Siguiendo a esta literatura, planteamos como hipótesis que las percepciones de desigualdad en Chile serán mayores entre quienes perciben la situación económica del país en forma negativa.

\section{El impacto de actitudes políticas en las percepciones de desigualdad}

Desde otro ángulo, la investigación académica ha mostrado que existe una importante relación entre la posición política de los individuos y las percepciones que ellos tienen sobre la desigualdad. En efecto, se encuentra en forma consistente que se percibe mayor desigualdad -y se evalúa en forma negativa- entre quienes se identifican con la izquierda (Bartels, 2008; McCall, 2013; Page \& Jacobs, 2009). En este trabajo entonces, esperamos observar una relación entre posición política y percepciones de desigualdad en Chile acorde con estos resultados.

En esta línea se inserta el único análisis detallado sobre percepciones de desigualdad en Chile (Castillo et al., 2012). En este trabajo los autores evalúan percepciones de desigualdad utilizando tres medidas diferentes: brechas de ingresos entre profesiones, percepción general de desigualdad y percepción diagramática de desigualdad para el año 2009. Con respecto a las percepciones diagramáticas -que son las que estudiaremos aquí- los autores muestran que están positivamente relacionadas con el estatus económico subjetivo, es decir que a mayor estatus, la sociedad chilena se percibe como más desigual. También indican que no se observan, para ese año, asociaciones estadísticamente significativas con la posición política de los entrevistados. En este trabajo avanzamos en esta misma línea, ampliando el número de mediciones utilizadas para observar los determinantes de las percepciones de desigualdad en un período de más de 13 años (2000-2013), lo que no se había realizado hasta ahora.

\section{Métodos y datos}

Este trabajo se basa en el análisis de datos obtenidos por las encuestas del Centro de Estudios Públicos (CEP) los años 2000, 2009, 2012 y 2013. En esas oportunidades se incluyeron en el cuestionario preguntas asociadas a la desigualdad económica (en 2000 y 2009, corresponden al módulo de Desigualdad desarrollado por el International Social Survey Programme, ISSP), y a cómo las personas perciben los niveles de desigualdad existentes.

Las encuestas del CEP que utilizaremos son representativas de la población nacional, realizadas a la población mayor de 18 años residente en el país, con muestras 
probabilísticas de alrededor de 1.500 casos en cada oportunidad. Los detalles técnicos de cada una de estas encuestas se pueden encontrar en el Anexo. A continuación describiremos las variables y los procedimientos de análisis utilizados en este estudio. La Tabla $\mathrm{N}^{\circ}$, por su parte, presenta los estadísticos descriptivos de cada una de ellas.

\section{Variable dependiente: Imágenes de desigualdad}

Para este trabajo, como señalamos anteriormente, utilizamos la pregunta sobre las imágenes de desigualdad económica (ver Figura $\mathrm{N}^{\circ}$ 1). Esta pregunta fue recodificada de forma tal que números mayores representan mayor percepción de desigualdad. En otras palabras, la imagen Tipo A tiene un valor 5, la Tipo B un valor 4, hasta la imagen Tipo E con un valor 1 .

\section{Variables independientes: Factores económicos}

Cuatro variables que miden factores económicos fueron incluidas en los análisis. Primero, una pregunta que mide la posición económica percibida de los entrevistados (TOPBOT), la cual pide a los entrevistados ubicarse en una escala de 1 a 10, donde 1 representa al sector más bajo y 10 representa al sector más alto ${ }^{1}$.

En segundo lugar, se incluyó el nivel educacional de los entrevistados, medidos como el número de años de estudios aprobados ${ }^{2}$.

Tercero, se utilizó una pregunta que evalúa la percepción de los ciudadanos con respecto a la situación económica del país ${ }^{3}$. Con ella se construyeron dos variables dummy: la primera, ECON_B, indica a los entrevistados que consideran que la situación económica del país es buena o muy buena; la segunda, ECON_M, indica a los entrevistados que consideran que la situación económica es mala o muy mala (la categoría base en los análisis son aquellos que consideran que la situación económica es regular).

Cuarto, se incluyó una variable dummy, PROGRE, que identifica a los entrevistados que creen que el país está progresando (la categoría base son aquellos que consideran que el país está estancado o en decadencia) ${ }^{4}$.

\footnotetext{
${ }^{1} \mathrm{P}$. En nuestra sociedad, hay grupos que tienden a ubicarse en los niveles más altos y grupos que tienden a ubicarse en los niveles más bajos. Usando la siguiente escala, donde 1 es el nivel más bajo y 10 es el nivel más alto, ¿dónde se ubica usted?

${ }^{2}$ P. Sin tomar en cuenta las repeticiones de curso, ¿cuántos años de estudios aprobados tiene usted?

${ }^{3}$ P. ¿Cómo calificaría usted la actual situación económica del país? Muy buena, buena, regular, mala o muy mala.

${ }^{4} \mathrm{P}$. ¿Usted cree que en el momento actual Chile está progresando, estancado o en decadencia?
} 


\section{Variables independientes: Factores políticos}

Dos preguntas asociadas a factores políticos fueron incluidas en el análisis. Primero, APRUEBA, es una variable dummy que indica el porcentaje de personas que en cada oportunidad señaló que aprueban la labor del presidente ${ }^{5}$.

Adicionalmente incluimos variables que miden el porcentaje de personas que se identifican con la Alianza y con la Nueva Mayoría. Para construir estas variables utilizamos las preguntas de identificación partidaria ${ }^{6}$ y agrupamos a quienes señalaron identificarse con la UDI o RN en la Alianza, y a quienes se identifican con el PDC, PRSD, PS, PPD y PC como partidarios de la Nueva Mayoría.

\section{Tabla $\mathbf{N}^{\circ}$ 1: Estadísticos descriptivos}

\begin{tabular}{|c|c|c|c|c|c|}
\hline & $\mathbf{N}$ & Mín. & Máx. & Media & Std. Dev. \\
\hline $\begin{array}{l}\text { IMAGEN } \\
(1=\text { poca desigualdad, } 5=\text { mucha desigualdad })\end{array}$ & 5.729 & 1 & 5 & 3,78 & 1,067 \\
\hline $\begin{array}{l}\text { TOPBOT } \\
\text { (Dónde se ubica usted: } 1=\text { nivel más bajo; } 10=\text { nivel más alto) }\end{array}$ & 5.847 & 1 & 10 & 4,26 & 1,629 \\
\hline $\begin{array}{l}\text { EDUC } \\
\text { (Años de estudios) }\end{array}$ & 5.958 & 0 & 25 & 10,82 & 4,373 \\
\hline $\begin{array}{l}\text { ECON_M } \\
\text { (Situación económica actual país } 1=\text { mala })\end{array}$ & 5.963 & 0 & 1 & 0,35 & 0,477 \\
\hline $\begin{array}{l}\text { ECON_B } \\
\text { (Situación económica actual país } 1 \text { = Buena) }\end{array}$ & 5.963 & 0 & 1 & 0,17 & 0,379 \\
\hline $\begin{array}{l}\text { PROGRE } \\
\text { (Chile está: } 1 \text { = progresando) }\end{array}$ & 5.819 & 0 & 1 & 0,43 & 0,495 \\
\hline $\begin{array}{l}\text { ALIANZA } \\
\text { (1= Se identifica con partidos de la Alianza) }\end{array}$ & 5.809 & 0 & 1 & 0,11 & 0,313 \\
\hline $\begin{array}{l}\text { CONCERTA } \\
(1=\text { Se identifica con partidos de la Concertación }+ \text { PC) }\end{array}$ & 5.809 & 0 & 1 & 0,24 & 0,426 \\
\hline $\begin{array}{l}\text { APRUEBA } \\
\text { (Aprobación del presidente } 1=\text { Aprueba) }\end{array}$ & 5.787 & 0 & 1 & 0,44 & 0,496 \\
\hline $\begin{array}{l}\text { SEXO } \\
(1=\text { Hombre })\end{array}$ & 5.991 & 0 & 1 & 0,49 & 0,500 \\
\hline $\begin{array}{l}\text { EDAD } \\
\text { (Edad en años) }\end{array}$ & 5.991 & 18 & 97 & 42,61 & 17,001 \\
\hline $\begin{array}{l}\text { ECIVIL } \\
\text { (Estado civil } 1=\text { Casado) }\end{array}$ & 5.944 & 0 & 1 & 0,47 & 0,499 \\
\hline $\begin{array}{l}\text { TRABAJA } \\
\text { (Situación laboral: } 1=\text { Trabaja tiempo completo) }\end{array}$ & 5.941 & 0 & 1 & 0,49 & 0,500 \\
\hline
\end{tabular}

Fuente: elaboración propia

\footnotetext{
${ }^{5}$ P. Independientemente de su posición política, ¿usted aprueba o desaprueba la forma como [Nombre Presidente] está conduciendo su gobierno?

${ }^{6} \mathrm{P}$. De los siguientes partidos políticos que se presentan en esta tarjeta, ¿con cuál de ellos se identifica más o simpatiza más usted?
} 


\section{Otras variables de control}

Como variables de control incluimos también sexo, edad 7 , situación laboral ${ }^{8}$ y estado civil $^{9}$ de los entrevistados, así como variables que indican el año de medición.

\section{Procedimientos de análisis}

Para evaluar el impacto que factores económicos y políticos tienen sobre las percepciones de desigualdad, utilizamos análisis de regresión múltiple y de regresión logística ordinal. Los resultados obtenidos son consistentes en ambos casos, por lo que aquí presentamos los resultados obtenidos con el primer procedimiento, dado que son más simples de interpretar. Estas regresiones se realizaron para cada uno de los años considerados, así como para una base que agrupó a las cuatro encuestas utilizadas.

\section{Resultados}

\section{¿Cuánta desigualdad se percibe?}

¿Cuánta desigualdad se percibe en Chile? ¿Cómo han variado esas percepciones entre el 2000 y el 2013? La Tabla $\mathrm{N}^{\circ} 2$ muestra los resultados obtenidos. Tal como se puede apreciar, las personas en Chile perciben un alto nivel de desigualdad, con alrededor de $25 \%$ de los entrevistados ubicando a Chile en la imagen A (mayor desigualdad) y alrededor de $44 \%$ identifica a Chile con la imagen B. Es decir y más allá de las variaciones que hay en el tiempo, ocurre que en los trece años que abarca el estudio, siempre más del 62\% de la población ha identificado a Chile con las dos imágenes que expresan mayores grados de desigualdad económica.

Tabla $N^{\circ}$ 2. Imágenes de desigualdad en Chile, 2000-2013

\begin{tabular}{|l|l|l|l|l|l|l|}
\hline & & & & & & \\
\end{tabular}

Fuente: elaboración propia

\footnotetext{
7 P. ¿Cuál es su edad?

${ }^{8}$ P. Escoja una de las siguientes alternativas, en función de si trabaja o no trabaja. Se codificó como 1 a quienes señalaron que trabajan tiempo completo y 0 a las otras alternativas.

${ }^{9}$ P. ¿Cuál es su estado civil o conyugal actual? Se codificó como 1 a quienes señalaron que están casados y viven con su esposo/a, y 0 a quienes tienen otro estado civil.
} 
Visto lo anterior, es interesante también subrayar que existen variaciones en las imágenes de desigualdad de los chilenos. Así, es notorio que el porcentaje de entrevistados que seleccionan la sociedad E (la más igualitaria), se mantiene estable en torno a un $3 \%$ de las preferencias. A su vez, quienes identifican a Chile con la sociedad representada en la imagen D (igualitaria) aumentan de $8 \%$ a $17 \%$. En este marco, queda claro que solo una porción muy minoritaria de chilenos identifica al país con modelos de igualdad relativamente altos. En segundo lugar, es llamativo que quienes identifican a Chile con la imagen $\mathrm{C}$ se mantienen estables, en torno a un $12 \%$ de los entrevistados en cada una de las mediciones. Finalmente, el porcentaje de quienes identifican a Chile con las imágenes A y B (los más desiguales), muestran tendencias de cambio que se anulan entre sí. Mientras el porcentaje de entrevistados que elige la imagen B baja de $49 \%$ a $39 \%$, el porcentaje que elige el tipo A llega a 30\% en 2013.

Con todo, si comparamos los promedios, cabe resaltar que los chilenos consideran que la sociedad chilena es un poco más igualitaria hoy que lo que la consideraban el año 2000, con promedios que van de 3,96 en 2000 a 3,76 en 2013 ( $t=4,899$, p < o,o01).

En síntesis, es posible apreciar un aumento leve, aunque estadísticamente significativo, en las percepciones más igualitarias del país. Sin embargo, pese a esta leve mejora en la evaluación de la desigualdad en Chile, la mayoría de los entrevistados sigue considerando al país como fundamentalmente desigual (alrededor de 70\% elige las sociedades Tipo A y Tipo B). Estos datos adicionalmente, están en línea con las estadísticas oficiales de ingreso y desigualdad reportadas por la encuesta CASEN que muestran una disminución de la desigualdad desde un índice de Gini de o,58 el año 2000 a un índice de 0,54 el año 2011 (CASEN, 2011).

Los datos obtenidos para Chile en los años 2000 y 2009 pueden ser comparados con otros obtenidos por el ISSP en 24 países. Tal como se observa en la Figura $\mathrm{N}^{\circ} 2$, tanto los niveles de desigualdad percibidos por los ciudadanos de los distintos países como sus trayectorias de cambio, muestran resultados diversos, no existiendo un patrón único: diez países (42\% del total) muestran un aumento estadísticamente significativo en las percepciones de desigualdad, mientras en ocho (33\%) ocurre lo contrario. Chile se encuentra en este último grupo junto a Australia, Bulgaria, Holanda y Suecia. Con todo, cabe también subrayar que Chile se encuentra entre los países con mayor percepción de desigualdad (en ambas mediciones) junto a Bulgaria, Polonia y Rusia. 


\section{Figura $\mathrm{N}^{\circ}$ 2: Imágenes de desigualdad en 24 países, 1999-2009 (promedios)}

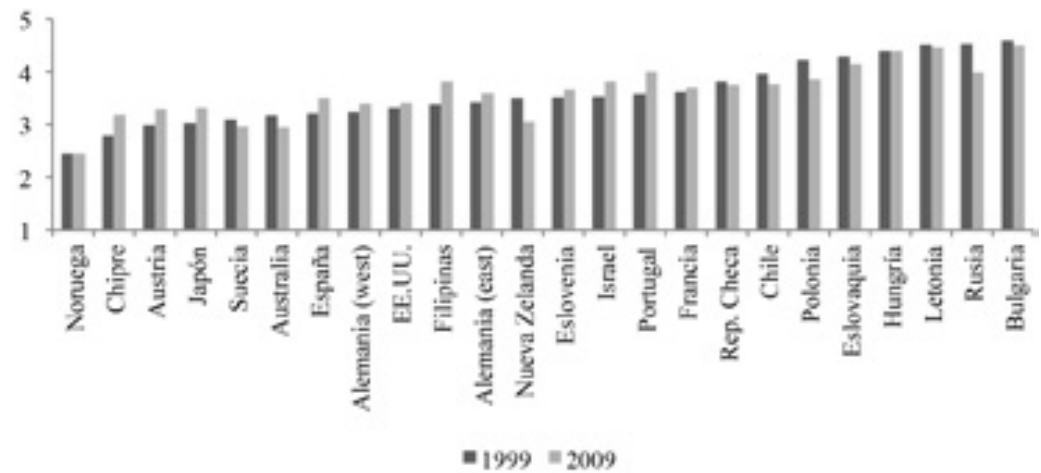

Fuente: ISSP (2014)

\section{El impacto de factores económicos y políticos en las percepciones de desigualdad}

El segundo objetivo de este trabajo es evaluar cómo y cuánto afectan el nivel socioeconómico de las personas, las percepciones sobre la situación económica del país y la posición política de los individuos en las percepciones de desigualdad. Como discutimos anteriormente, las percepciones están asociadas a niveles de ingreso y de educación, a la evaluación que los ciudadanos hacen de la situación económica del país y con la posición política de los entrevistados. Los resultados obtenidos se resumen en la Tabla $\mathrm{N}^{\circ} 3$, que explicamos a continuación.

Comencemos con el impacto estimado para los factores económicos incluidos en los modelos. La variable más importante para explicar las percepciones de desigualdad es el lugar en la escala social donde se ubican las personas (TOPBOT) o en otras palabras, el estatus socioeconómico subjetivo. Tal como se puede apreciar en la tabla 3, aquellas personas que se ubican en los sectores más altos de la escala social son aquellos que tienen una menor percepción de desigualdad, ceteris paribus. En otras palabras, tal como sugiere Schattschneider (1960), son los ciudadanos que se ubican más abajo en la escala quienes perciben una mayor desigualdad en el país. La variable que mide nivel educacional, otro componente tradicional del estatus socioeconómico de las personas, solo resulta ser estadísticamente significativa en 2013, mostrando que a mayor educación, mayor percepción de desigualdad, entregando evidencia para la hipótesis que sugiere que las percepciones de desigualdad son mayores entre quienes tienen mayores niveles de conocimiento.

El trabajo también demuestra que la percepción de progreso (PROGRE) y la de la situación económica actual del país (ECON_My ECON_B) tienen efectos estadísticamente significativos en el modelo global: la percepción de desigualdad es mayor, controlando 
otros factores, entre quienes consideran que la situación económica es negativa y entre quienes evalúan al país como estancado o en decadencia. Estos resultados corresponden a nuestras expectativas y son similares a los obtenidos por Cramer y Kaufman (2011). Al evaluar estos impactos año a año observamos que en general, la dirección de los efectos se mantiene constante, pero que adquieren significancia estadística solo en algunas oportunidades (la imagen del progreso en 2013 y la percepción de la situación económica en 2012).

Tabla $N^{\circ}$ 3. Resultados de los modelos de regresión

\begin{tabular}{|c|c|c|c|c|c|}
\hline & $\begin{array}{c}\text { Todas } \\
2000-2013\end{array}$ & 2000 & 2009 & 2012 & 2013 \\
\hline Constante & $\begin{array}{l}4.308 * * * \\
(0,081)\end{array}$ & $\begin{array}{l}4.076 * * * \\
(0,137)\end{array}$ & $\begin{array}{l}4.095 * * * \\
(0,152)\end{array}$ & $\begin{array}{l}3.977 * * * \\
(0,176)\end{array}$ & $\begin{array}{l}4.506 * * * \\
(0,170)\end{array}$ \\
\hline \multicolumn{6}{|c|}{ Factores económicos } \\
\hline TOPBOT & \begin{tabular}{|l|}
$-0,098 * * *$ \\
$(0,010)$ \\
\end{tabular} & \begin{tabular}{|l|}
$-0,070 * * *$ \\
$(0,016)$ \\
\end{tabular} & \begin{tabular}{|l|}
$-0,099 * * *$ \\
$(0,019)$ \\
\end{tabular} & \begin{tabular}{|l|}
$-0,049 *$ \\
$(0,024)$ \\
\end{tabular} & \begin{tabular}{|l}
$-0,155^{* * *}$ \\
$(0,026)$ \\
\end{tabular} \\
\hline EDUC & $\begin{array}{l}0,002 \\
(0,004)\end{array}$ & $\begin{array}{l}0,004 \\
(0,007)\end{array}$ & $\begin{array}{l}-0,011 \\
(0,008)\end{array}$ & $\begin{array}{l}-0,007 \\
(0,010)\end{array}$ & $\begin{array}{l}0,027 * * \\
(0,009)\end{array}$ \\
\hline PROGRE & $\begin{array}{l}-0,137 * * * \\
(0,033)\end{array}$ & $\begin{array}{l}0,016 \\
(0,062)\end{array}$ & $\begin{array}{l}-0,012 \\
(0,061)\end{array}$ & \begin{tabular}{|l|}
$-0,079$ \\
$(0,074)$ \\
\end{tabular} & $\begin{array}{l}-0,471 \text { *** } \\
(0,070) \\
\end{array}$ \\
\hline ECON_M & $\begin{array}{l}0,088 * * \\
(0,034)\end{array}$ & $\begin{array}{l}0,112 \\
(0,060)\end{array}$ & \begin{tabular}{|l|}
0,093 \\
$(0,064)$
\end{tabular} & $\begin{array}{l}0,213 * * \\
(0,076)\end{array}$ & $\begin{array}{l}0,046 \\
(0,073)\end{array}$ \\
\hline ECON_B & $\begin{array}{l}-0,089 * \\
(0,042)\end{array}$ & $\begin{array}{l}-0,069 \\
(0,094)\end{array}$ & $\begin{array}{l}-0,120 \\
(0,078)\end{array}$ & $\begin{array}{l}-0,020 \\
(0,084)\end{array}$ & \begin{tabular}{|l|}
$-0,032$ \\
$(0,084)$
\end{tabular} \\
\hline \multicolumn{6}{|c|}{ Factores políticos } \\
\hline Alianza & \begin{tabular}{|l|}
$-0,092 *$ \\
$(0,047)$
\end{tabular} & \begin{tabular}{|l|}
0,029 \\
$(0,084)$
\end{tabular} & $\begin{array}{l}-0,067 \\
(0,083)\end{array}$ & $\begin{array}{l}-0,077 \\
(0,113)\end{array}$ & \begin{tabular}{|l|}
$-0,015$ \\
$(0,115)$
\end{tabular} \\
\hline Concerta & \begin{tabular}{|l|}
$-0,042$ \\
$(0,036)$
\end{tabular} & $\begin{array}{l}0,053 \\
(0,059)\end{array}$ & $\begin{array}{l}-0,014 \\
(0,067) \\
\end{array}$ & \begin{tabular}{|l|}
$-0,097$ \\
$(0,083)$ \\
\end{tabular} & \begin{tabular}{|l|}
$-0,237 * *$ \\
$(0,085)$ \\
\end{tabular} \\
\hline Aprueba & $\begin{array}{l}-0,082 * \\
(0,034)\end{array}$ & $\begin{array}{l}-0,042 \\
(0,059)\end{array}$ & $\begin{array}{l}-0,029 \\
(0,065)\end{array}$ & $\begin{array}{l}-0,166 * \\
(0,082)\end{array}$ & $\begin{array}{l}-0,130 \\
(0,077) \\
\end{array}$ \\
\hline \multicolumn{6}{|c|}{ Variables de control } \\
\hline Sexo & \begin{tabular}{|l|}
0,047 \\
$(0,031)$ \\
\end{tabular} & \begin{tabular}{|l|}
$-0,044$ \\
$(0,057)$ \\
\end{tabular} & $\begin{array}{l}-0,071 \\
(0,060)\end{array}$ & \begin{tabular}{|l|}
$-0,005$ \\
$(0,068)$ \\
\end{tabular} & \begin{tabular}{|l|}
$0,261 * * *$ \\
$(0,063)$ \\
\end{tabular} \\
\hline Edad & $\begin{array}{l}0,000 \\
(0,001)\end{array}$ & \begin{tabular}{|l|}
0,001 \\
$(0,002)$
\end{tabular} & \begin{tabular}{|l|}
0,003 \\
$(0,002)$ \\
\end{tabular} & \begin{tabular}{|l|}
0,000 \\
$(0,002)$
\end{tabular} & \begin{tabular}{|l|}
$-0,002$ \\
$(0,002)$ \\
\end{tabular} \\
\hline E.Civil & $\begin{array}{l}0,088 * * \\
(0,031)\end{array}$ & $\begin{array}{l}0,002 \\
(0,055)\end{array}$ & \begin{tabular}{|l|}
0,108 \\
$(0,058)$
\end{tabular} & \begin{tabular}{|l|}
0,124 \\
$(0,068)$
\end{tabular} & $\begin{array}{l}0,130 * \\
(0,068)\end{array}$ \\
\hline Trabaja & $\begin{array}{l}-0,057 \\
(0,032)\end{array}$ & $\begin{array}{l}0,061 \\
(0,059)\end{array}$ & $\begin{array}{l}0,119 * \\
(0,062)\end{array}$ & $\begin{array}{l}0,067 \\
(0,069)\end{array}$ & $\begin{array}{l}-0,269 * * * \\
(0,064)\end{array}$ \\
\hline 2009 & $\begin{array}{l}-0,143 * * \\
(0,042) \\
\end{array}$ & & & & \\
\hline 2012 & $\begin{array}{l}-0,258^{* * *} \\
(0,044)\end{array}$ & & & & \\
\hline 2013 & $\begin{array}{l}-0,111 * \\
(0,044)\end{array}$ & & & & \\
\hline $\mathrm{N}$ & 5,142 & 1,231 & 1,355 & 1,280 & 1,276 \\
\hline Adj. R2 & 0,048 & 0,017 & 0,048 & 0,027 & 0,121 \\
\hline
\end{tabular}

$* \mathrm{p}<0.05 ; * * \mathrm{p}<0.01 ; * * * \mathrm{p}<0.001$

Fuente: elaboración propia 
¿Y qué nos dice el estudio con respecto a los factores políticos? A diferencia de lo que ocurre en otros países, ellos no parecen ser importantes para el caso chileno. En efecto, quienes aprueban la gestión del presidente tienen una menor percepción de desigualdad, ceteris paribus. Sin embargo, ese efecto emerge con fuerza y significancia estadística solo para la medición del 2012. La identificación con las principales coaliciones políticas del país produce efectos que no son estadísticamente significativos y que van contra lo esperado. Tampoco encontramos evidencia de que la percepción de desigualdad es mayor entre quienes se identifican con la izquierda o con los partidos políticos que se ubican a la izquierda del espectro político. Como indica la Tabla $\mathrm{N}^{\circ} 3$, en el caso de Chile identificarse con la Nueva Mayoría no aumenta la percepción de desigualdad sino que la disminuye (con respecto a aquellos que no se identifican con ninguno de los pactos) y este efecto es además, estadísticamente significativo en 2013, en la antesala de la elección presidencial de ese año. La identificación con la Alianza genera, como se esperaba, una menor percepción de desigualdad, pero solo al unir los cuatro años, sin observarse efectos estadísticamente significativos en ninguna de las mediciones individuales.

Finalmente, las variables de control en general no tienen efectos independientes que sean estadísticamente significativos, salvo en algunos casos particulares. Los hombres tienen una percepción de mayor desigualdad económica que las mujeres en 2013 , aquellos que están casados también perciben mayor desigualdad y aquellos que trabajan jornada completa perciben menor desigualdad, ceteris paribus. En el modelo que incluye los cuatro años además, las variables que indican el año de medición (año 2000 como categoría base) son todas estadísticamente significativas y muestran la tendencia a la baja en las percepciones de desigualdad en Chile.

Estos resultados sugieren varias observaciones respecto de los determinantes de las percepciones de desigualdad en Chile, y del valor relativo que factores económicos y políticos tienen en ellas. Primero, como señalamos anteriormente, los factores económicos son los que, en promedio, tienen un mayor impacto en qué tan desigual es percibida la sociedad chilena. En efecto, auto posicionarse en sectores más desaventajados y tener una evaluación negativa de la situación económica del país lleva a los ciudadanos a representar a Chile con una imagen de mayor desigualdad. Estos dos resultados -junto con el menor impacto observado respecto del impacto de la educación- permiten señalar que las percepciones de desigualdad en el país se presentan entre quienes se ven más desaventajados o son más afectados por el sistema económico.

Por otra parte, los resultados obtenidos muestran que las variables políticas tienen un menor impacto en las percepciones de desigualdad. A diferencia de resultados obtenidos en otros países, las personas que se identifican con la izquierda -en este caso con algunos de los partidos que componen la actual Nueva Mayoría- no perciben mayor desigualdad que aquellos que se identifican con la derecha. Es entre aquellos que no se 
identifican -la categoría base en el análisis- que hay imágenes de desigualdad mayores. Lo mismo ocurre en el caso de la aprobación presidencial. Es entre quienes no aprueban la labor del presidente donde la percepción de desigualdad es mayor.

\section{Conclusiones}

¿Cuánta desigualdad es percibida por los chilenos? ¿Cuál es el impacto de factores económicos y políticos en las percepciones de desigualdad? Utilizando datos de encuestas desde el año 2000 al 2013, en este trabajo analizamos las imágenes de desigualdad de ciudadanos chilenos. Los resultados obtenidos pueden ser sintetizados de la siguiente manera.

La sociedad chilena es percibida como una con altos niveles de desigualdad. Al igual que lo que se observa en las cifras de distribución de ingreso oficiales, las personas perciben al país como uno con elevados niveles de desigualdad, mostrando una leve mejoría con el paso del tiempo. En efecto, al utilizar una pregunta que evalúa la desigualdad en el país a través del uso de imágenes asociadas a la distribución de las personas en una sociedad, los chilenos eligen como mejor descriptor del país aquellas imágenes que muestran más desigualdad: donde solo unos pocos se ubican en las posiciones superiores y la gran mayoría se ubica en las posiciones inferiores. Al mismo tiempo, si comparamos los resultados obtenidos en 2000 y 2013, se observa una leve mejoría en los niveles de desigualdad percibidos, pero manteniendo porcentajes sustantivos de los entrevistados en las imágenes que presentan mayor desigualdad.

En términos comparados, Chile se ubica dentro del grupo de países con mayor nivel de desigualdad percibida (de los medidos por ISSP), pero a su vez también dentro de aquellos en los que ha mejorado la imagen de desigualdad.

Los factores económicos son los que más ayudan a explicar las percepciones de desigualdad de los chilenos. Los resultados muestran que el auto-posicionamiento en la escala social de los entrevistados es la variable que mayor efecto tiene -y de manera constante en todos los modelos realizados- en las imágenes de desigualdad. Estos datos indican que son aquellos que se ubican en los niveles más bajos de la escala socioeconómica quienes perciben un mayor nivel de desigualdad en el país. Otras variables que miden nivel socioeconómico, como el nivel educacional, tienen efectos que no son estadísticamente significativos.

$\mathrm{Al}$ mismo tiempo, la percepción que las personas tienen de la situación económica del país también tiene un efecto importante en las imágenes de desigualdad. Los datos muestran que, en concordancia con resultados obtenidos en otras investigaciones, quienes tienen una evaluación más negativa de la situación económica del país, son quienes tienden también a indicar que Chile es un país más desigual.

Los resultados asociados a factores políticos muestran que por una parte, la posición política de las personas no tiene un efecto relevante en las percepciones de desigualdad. 
Más que una diferencia entre aquellos que se identifican con la izquierda o con la derecha, lo que se observa con estos datos para Chile, es que los que no se identifican con ninguna coalición política son quienes perciben al país como más desigual. Esto contrasta con resultados de la investigación comparada, donde los factores políticos sí son relevantes.

La desigualdad económica es un tema que, a partir de la elección presidencial de 2013, se encuentra plenamente instalado en la discusión política pública. En este contexto es de esperar que su relevancia aumente también en las prioridades de la opinión pública. Una mayor relevancia pública de este tema, puede producir cambios en los niveles de desigualdad que se perciben -al aumentar el conocimiento general- y esas percepciones pueden llegar a tener consecuencias políticas importantes. Conocer cuánta desigualdad perciben los chilenos y qué factores están más asociados a ella, son elementos importantes para el debate que parece ya instalado a nivel del debate de políticas públicas. Es allí que este artículo pretende aportar al debate. Creemos que investigaciones futuras debieran centrarse en las consecuencias que a nivel de actitudes y conductas, puedan tener las percepciones de desigualad en los ciudadanos.

\section{Referencias}

American Association for Public Opinion Research, AAPOR (2011). Standard Definitions. Final Dispositions of Case Codes and Outcome Rates for Surveys. American Association for Public Opinion Research. Recuperado de www.aapor.org

Anderson, C., \& Singer, M. (2008). The Sensitive Left and the Impervious Right: Multilevel Models and the Politics of Inequality, Ideology, and Legitimacy in Europe. Comparative Political Studies, 41(4/5), 564-599.

Anderson, C., \& Beramendi, P. (2012). Left Parties, Poor Voters, and Electoral Participation in Advanced Industrial Societies. Comparative Political Studies, 45(6), 714-746.

Austen, S. (1999). Norms of Inequality. Journal of Economic Issues, 33(2), 435-442.

Bartels, L. (2008). Unequal Democracy. The Political Economy of the New Gilded Age. New York: Russell Sage Foundation \& Princeton University Press.

Blofield, M., \& Luna, J. (2011). Public Opinion on Income Inequalities in Latin America. En Blofield, M. (Ed.). The Great Gap. Inequality and the Politics of Redistribution in Latin America (pp. 147-181). Pennsylvania: The Pennsylvania State University Press.

CASEN (2011). Distribución del Ingreso CASEN 2011. Encuesta de Caracterización Socioeconómica Nacional. Chile: Ministerio de Desarrollo Social. Recuperado de http://observatorio.ministeriodesarrollosocial.gob.cl/layout/doc/casen/oo1_ingreso_2011.pdf 
Castillo, J, Miranda, D., \& Carrasco, D. (2012). Percepción de Desigualdad Económica en Chile: Medición, Diferencias y Determinantes. Psykhe, 21(1), 99-114.

Centro de Estudios Públicos, CEP (2000, marzo-abril). Estudio Nacional de Opinión Pública $N^{o}$ 11. Santiago: Centro de Estudios Públicos.

Centro de Estudios Públicos, CEP (2009, mayo-junio). Estudio Nacional de Opinión Pública $N^{o}$ 3o. Santiago: Centro de Estudios Públicos.

Centro de Estudios Públicos, CEP (2012, julio-agosto). Estudio Nacional de Opinión Pública $N^{o} 38$. Santiago: Centro de Estudios Públicos.

Centro de Estudios Públicos, CEP (2013, julio-agosto). Estudio Nacional de Opinión Pública $N^{\circ}$ 4O. Santiago: Centro de Estudios Públicos.

CNN Chile (2014, marzo 11). Michelle Bachelet desde La Moneda: "Chile tiene solo un gran adversario y se llama desigualdad”. CNN Chile. Recuperado de http:// cnnchile.com/noticia/2014/o3/11/michelle-bachelet-desde-la-moneda-chiletiene-solo-un-gran-adversario-y-se-llama-desigualdad

Converse, P. E. (2000). Assessing the Capacity of Mass Electorates. Annual Review of Political Science, 3, 331-353.

Cramer, B. D., \& Kaufman, R. R. (2011. Views of Economic Inequality in Latin America. Comparative Political Studies, 44(9), 1206-1237.

Cuneo, C. (1996). International images of social inequality: A ten-country comparison. En Frizzell, A. S., \& Pammett, J. H. (Eds.). Social inequality in Canada (pp. 3165). Toronto: Carleton University Press.

Evans, M. D. R., Kelley, J., \& Kolosi, T. (1992). Images of Class: Public Perceptions in Hungary and Australia. American Sociological Review, 57, 461-482.

ISSP (2014). International Social Survey Programme: Social Inequality I-IV - ISSP 1987-1992-1999-2009. GESIS Data Archive, Cologne. ZA589o Data file Version 1.o.o. http://dx.doi.org/10.4232/1.11911.

Kelley, J., \& Evans, M. D. R. (1993). The Legitimation of Inequality: Occupational Earnings in Nine Nations. American Journal of Sociology, 99(1), 75-125.

Kelley, J., \& Zagorski, K. (2004). Economic Change and the Legitimation of Inequality: The Transition from Socialism to the Free Market in Central-East Europe. Research in Social Stratification and Mobility, 22, 319-364.

McCall, L. (2005). Do They Know and Do They Care? Americans'Awareness of Rising Inequality. Paper to be presented at the Russell Sage Foundation Social Inequality Conference University of California, Berkeley. May, 2005 
McCall, L. (2009). Americans'Social Policy Preferences in the Era of Rising Inequality. Paper to be presented at the New York University School of Law Colloqium on Tax Policy and Public Finance, Spring 2009.

McCall, L. (2013). The Undeserving Rich. American Beliefs about Inequality, Opportunity and Redistribution. Cambridge: Cambridge University Press.

Meltzer, A., \& Richard, S. (1981). A Rational Theory of the Size of Government. Journal of Political Economy, 89(5), 914-927.

OCDE (2011). Divided We Stand: Why Inequality Keeps Rising. OECD Publishing.

ORBE (2007, agosto 3). Monseñor Goic: Sueldo mínimo debería convertirse en sueldo ético. Emol. Nacional. Recuperado de http://www.emol.com/noticias/nacional/2007/o8/o3/264674/monsenor-goic-sueldo-minimo-deberia-convertirseen-sueldo-etico.html

Page, B., \& Jacobs, L. (2009). Class War? Chicago: The University of Chicago Press.

Schattschneider, E. (1960). The Semi-Sovereign People: A Realist's View of Democracy in America. New York: Holt, Reinhart, and Winston.

Segovia, C., \& Gamboa, R. (2012). Chile: El año en que salimos a la calle. Revista de Ciencia Política, 32(1), 65-85.

Solt, F. (2008). Economic Inequality and Democratic Political Engagement. American Journal of Political Science, 52(1), 48-60.

Solt, F. (2010). Does Economic Inequality Depress Electoral Participation? Testing the Schattschneider Hypothesis. Political Behavior, 32(2), 285-301.

Zaller, J. (1992). The Nature and Origins of Mass Opinion. Cambridge: Cambridge University Press. 
Anexo: Características técnicas de las encuestas utilizadas

\begin{tabular}{|l|l|l|l|l|}
\hline & \multicolumn{1}{|c|}{$\begin{array}{c}\text { Encuesta } \\
\text { marzo-abril } \\
\mathbf{2 0 0 0}\end{array}$} & $\begin{array}{c}\text { Encuesta } \\
\text { mayo-junio } \\
\mathbf{2 0 0 9}\end{array}$ & $\begin{array}{l}\text { Encuesta julio- } \\
\text { agosto 2012 }\end{array}$ & $\begin{array}{l}\text { Encuesta julio- } \\
\text { agosto 2013 }\end{array}$ \\
\hline $\begin{array}{l}\text { Tamaño de la } \\
\text { muestra }\end{array}$ & 1.503 & 1.505 & 1.512 & 1.471 \\
\hline Fecha de terreno & $\begin{array}{l}18 \text { de marzo }-4 \\
\text { de abril de } 2000\end{array}$ & $\begin{array}{l}14 \text { de mayo }-3 \\
\text { de junio de } 2009\end{array}$ & $\begin{array}{l}5 \text { de julio }-9 \text { de } \\
\text { agosto de } 2012\end{array}$ & $\begin{array}{l}13 \text { de julio }-18 \\
\text { de agosto de } \\
2013\end{array}$ \\
\hline $\begin{array}{l}\text { Tasa de } \\
\text { respuesta RR1 } \\
\text { (AAPOR, 2011) }\end{array}$ & $90 \%$ & $88 \%$ & $81 \%$ & $79 \%$ \\
\hline
\end{tabular}

Fuente: elaboración propia

El método de selección de las muestras en todas estas oportunidades fue probabilístico y aleatorio para cada una de las etapas en las que se realizó. En una primera etapa se seleccionaron 312 unidades primarias de muestreo (UPM) que correspondieron a manzanas distribuidas a lo largo del país. En la segunda etapa y utilizando un muestreo sistemático, se seleccionaron seis viviendas dentro de cada manzana elegida. Finalmente, dentro de cada hogar se realizó la selección del individuo utilizando una tabla de números aleatorios. 